\title{
Perception of Patients and Other Health Care Professionals about Nurses at the University College Hospital, Ibadan, Oyo State, Nigeria
}

\author{
Modupe 0. Oyetunde ${ }^{1 *}$, Ononaiwu M. Kelechi ${ }^{1}$, Mary O. Oyediran² \\ ${ }^{1}$ Department of Nursing, College of Medicine, University of Ibadan, Ibadan, Nigeria \\ ${ }^{2}$ University College Hospital, Ibadan, Nigeria \\ Email: "modupeoyetunde@gmail.com, michelle.okwundu@gmail.com, niksem@yahoo.com
}

Received 19 October 2014; revised 18 November 2014; accepted 28 November 2014

Academic Editor: Jayanthi Radhakrishnan, College of Nursing, Sultan Qaboos University, Sultanate of Oman

Copyright (C) 2014 by authors and Scientific Research Publishing Inc.

This work is licensed under the Creative Commons Attribution International License (CC BY).

http://creativecommons.org/licenses/by/4.0/

(c) (i) Open Access

\section{Abstract}

Objective: To explore the perception of patients and other health care professionals about the attitude and behavior of nurses working at the University College Hospital Ibadan Oyo State. Background: Observation has shown that despite the efforts nurses put into carrying out their duties, the acknowledgement of a job well done from co-professionals and patients still leaves much to be desired. Could this be due to impressions formed about nurses? Hence, this study attempts to explore the perception of patients and other health care professionals about nurses. Methods: Two hundred (200) consented respondents were randomly selected for this study. This consists of 165 patients and 35 doctors representing other health care professionals. Data were collected through a pretested questionnaire. Analysis was done by using SPSS version 16.0. Result: Results showed that $68 \%$ of patients and $58 \%$ of doctors perceived that nurses were competent. About $75 \%$ of patients and $54 \%$ of doctors agreed that the nurses had adequate skills. Patients $(70 \%)$ and doctors $(49 \%)$ agreed that the nurses had a positive attitude towards work. About $74 \%$ of patients and $59 \%$ of doctors agreed to the fact that the nurses maintained a professional demeanor. Findings also showed that patients rated the nurses higher than the doctors did. A significant difference was found between the perception of patients and doctors about the communication skills of nurses ( $t$ $=2.423 ; \mathrm{df}=198 ; \mathrm{p}=0.016$ ). Conclusion: The study shows relative satisfaction with the quality of nurse's work, perceptions of people about their attitudes and behaviors. Nurses could improve on how they relate with other health care providers to achieve positive patient care outcomes.

\footnotetext{
*Corresponding author.
}

How to cite this paper: Oyetunde, M.O., Kelechi, O.M. and Oyediran, M.O. (2014) Perception of Patients and Other Health Care Professionals about Nurses at the University College Hospital, Ibadan, Oyo State, Nigeria. Open Journal of Nursing, 4, 947-955. http://dx.doi.org/10.4236/ojn.2014.413101 


\section{Keywords}

\section{Perception, Nurses, Patients, Health Care Professionals, Nigeria}

\section{Introduction}

Nursing is a helping, independent profession that provides services that contribute to the health of people. Its status as a profession is important because it reflects the value society places on the services of nurses and the centrality of the services to the good of the society [1].

Scrutinizing the role and services of nurses; attributes such as their knowledge, skills and attitudes can be used to discern and describe how effective they are in carrying out their duties as professionals. Effectiveness includes their ability to utilize a variety of communication skills, demonstration of sensitivity and gentleness when dealing with others. Their ability to show organization at the work place and ability to utilize problem-solving techniques all performed in a caring manner and to appropriate standards [2].

However, the detailed history of this profession that combines scientific principles, technical skills and personal attributes cannot be precisely relayed. Records hold that nursing came to limelight in 1854 when Florence Nightingale started the battlefield with other 38 nurses and cared for the sick and injured men during the Crimean war in England. Her persistent dedicated service and experiences paid off by making her famous and recognized as "the lady with the lamp". Her service resulted in complete change in nursing profession and led to the beginning of professional nursing. She combined Christian ideals, strict discipline and a sense of mission to open the door for what is known today as the nursing profession [3].

The ability of nurses to plan and organize their work will be of little benefit to patients, clients or other health professionals if the attitudes that nurses are expected to exhibit (such as, caring and patience) are not presented; therefore, it is important for nurses to integrate their knowledge, abilities and skills with attitudes of high standards as an essential key to performing activities with competence [2]. In agreement with this, Dougherty and Lister [4] opined that nurses of all cadres and disciplines have an ethical, moral and professional responsibility to disseminate their unique skills and knowledge to clients, colleagues, peers and fellow professionals with the utilization of good communication skills.

When dealing with clients, caring for someone or even interacting with a fellow professional, nurses are constantly being observed and through these observations, impressions are formed. Some of these impressions are based on parameters such as knowledge, appearance, competence (technical, interpersonal and critical thinking skills), character, and commitment to work among other things [5]. Whether good or bad, these impressions usually (and very fast) spread around the health facility and then to the larger community.

This study was anchored on the study of Imogene King who developed a conceptual model for nursing in the mid 1960's with the idea that human beings are open systems interacting with the environment [6]. The central focus of King's framework includes three interacting systems with each system having its own distinct group of concepts and characteristics. These systems include: personal systems, interpersonal systems, and social systems and they provide the basis for the development of the Theory of Goal Attainment [7]. The personal system represents the patient and other health care professionals who will have cause to relate with the nurse at the interpersonal system phase. The interaction that occurs at the interpersonal system influences the kind of perception formed by the personal system about the nurse who is at the pivot of this interaction. These interactions and perceptions are based on the influence of external forces such as governing bodies, culture and previous orientation which make up the social system. This study captures attributes that others might consider important for effective nursing care.

\section{Research Questions:}

1. What are the patients and other health care professionals' perception about the competence of nurses?

2. How do patients and other health care professionals rate the communication skills of nurses?

3. What are the patients and other health care professionals' perception about the attitude of nurses towards work?

4. How do patients and other health professionals describe nurses in terms of their professional demeanor? 


\section{Materials and Methods}

The study was a descriptive cross-sectional study conducted at the medical and surgical out-patient clinics of the University College Hospital Ibadan. The Hospital is the first Teaching Hospital in West Africa and it is owned and funded by the Federal Government of Nigeria. About six thousand patients (6000) are seen every month at the chosen outpatient clinics and the cases attended to range from renal, psychiatric, pulmonary, cardiac, to all forms of surgical cases.

Study population: this consists of patients and doctors within the study setting. The patients and doctors were randomly selected for this study.

Inclusion criteria:

1. Willingness to participate.

2. Patients who have been previously admitted in the hospital.

3. Doctors who have been working for at least 6 months in the hospital.

Sampling technique and sample size determination: Purposive sampling technique was used to select the health institution based on the type of services being rendered. Simple random sampling technique was be used to select patients from medical outpatients and surgical outpatients. In order to ensure equal representation of doctors, we categorized all the doctors working at the medical and surgical units of the same facility who represented other health care professionals into different strata based on their cadres. Within each cadre of doctors used for the study, simple random sampling method was used to select the doctors to be interviewed.

The sample size for the survey was calculated using the formula for sample size determination by Yamane (1967) in [8] as shown below.

$$
n=\frac{N}{1+N(e)^{2}}
$$

whereby; $n$ is required sample size.

$N$ is the total population.

$e$ is the error of tolerance (0.05).

In all, the total number of respondents selected for this study was 200. This consists of 165 patients and 35 doctors.

Instrument: A self-administered questionnaire of 28 items divided into five sections was used for the survey. It was developed after thorough literature review. Section A of the structured interview guide consisted questions on socio-demographic data of respondents. Section B gathered data on perception of respondents about competence of nurses, Section $C$ gathered data on perception of respondents about the communication skills of nurses. Section D gathered data on the perception of respondents about the attitude of nurses towards work. Section E gathered data on the perception of respondents about the professional demeanor of nurses.

The instrument was assessed for face validity, clarity and adequacy. The questionnaire reliability was pretested among ten (10) patients and ten (10) doctors in another health facility not selected for this study but shared similar characteristics as the subjects under study. The result shows that the values of Cronbach's coefficient alpha were satisfactory at 0.845 , indicating questions in each construct are measuring a similar concept.

Ethical Consideration: Participation was voluntary and participants were allowed to withdrawal at any stage. Confidentiality of person and information were assured and there was no harm done to individuals or organizations. Ethical approval was obtained from the ethical review committee of the University of Ibadan/University College Hospital Ibadan. The patient and the doctors were provided with information about the study. Oral and written consents were obtained before the administration of the questionnaire.

Statistical Analysis: Statistical analysis was done by using Statistical Package for Social Science (SPSS) version 16.0. Reliability coefficient of the questionnaire was done by using Cronbach's coefficient alpha. The results gathered were analyzed by using descriptive statistics while Independent T-test and one-way analysis of variance (anova) were used to test the hypothesis at alpha $5 \%$.

\section{Results}

Socio-Demographic Characteristics: Table 1 and Table 2 summarize the characteristics of the respondents. Out of the 200 participants, $82.5 \%$ were patients and $17.5 \%$ were health care professionals (doctors). The 
Table 1. Frequency analysis of the respondents.

\begin{tabular}{ccc}
\hline Respondents & Frequency & Percentage (\%) \\
\hline Patient & 165 & 82.5 \\
Medical Doctors & 35 & 17.5 \\
Total & 200 & 100.0 \\
\hline
\end{tabular}

Table 2. Descriptive analysis of the health care professionals (doctors) by cadre.

\begin{tabular}{ccc}
\hline & N & Percentage (\%) \\
\hline Consultants & 10 & 28.5 \\
Senior Registrars & 11 & 31.6 \\
Registrars & 8 & 22.8 \\
House officers & 6 & 17.1 \\
Total & 35 & 100.0 \\
\hline
\end{tabular}

doctor's cadres were Consultants (28.5\%), Senior Registrars (31.6\%), Registrars (22.8\%), and House officers (17.1\%).

Perception of patients and doctors about the competence of nurses: About $75.1 \%$ patients agreed that nurses perform procedures with minimal mistakes while $51.4 \%$ of doctors agreed that nurses perform procedures with minimal mistakes. $82.8 \%$ of the doctors agreed that nurses can handle hospital equipment compared with $76.4 \%$ of the patients who agreed that nurses handle hospital equipment adequately. Also $69.1 \%$ of the patients believe in the ability of the nurses to multitask, while $48.6 \%$ of the doctors agreed to this. $72.7 \%$ of patients agreed that nurses had good interpersonal relationship with others while $60 \%$ of the doctors agreed with this statement.

Majority of the patients $73.4 \%$ agreed that nurses possess good teaching skills, while $42.9 \%$ of the doctors of agreed to this. Also, most of the patients and doctors about $63.6 \%$ and $71.4 \%$ respectively agreed that nurses of higher cadre were more efficient than the junior nurses and the study also revealed that $55.1 \%$ of the patients agreed that the nurses generally have good knowledge about their conditions while $45.7 \%$ of the doctors agreed and $48.6 \%$ of the doctors disagreed (Table 3 and Table 4 ).

Perception of patients and doctors about the communication skills of nurses: From Table 5 and Table 6, 72.7\% patients agreed that nurses treat others with respect, while $51.5 \%$ doctors agreed to this. $86.7 \%$ patients agreed that nurses speak with confidence with $60 \%$ of the doctors agreeing to this. Also, $72.1 \%$ of patients agreed that nurses have a good command of the English language while $60 \%$ of doctors agreed to this statement. $80 \%$ of patients agreed that the nurses work amicably with other members of the health team while $51.5 \%$ of doctors agreed that the nurses work amicably with other members of the health team.

Perception of patients and doctors about the attitude of nurses towards their work: $70 \%$ of the total patient populace agreed that nurses generally have a positive attitude toward their work while $49 \%$ of doctors agree, with 35\% doctors disagreeing that nurses have a positive attitude toward their job (Figure 1 and Figure 2).

Perception of patients and doctors about the professional demeanor of nurses: $70.9 \%$ of patients agreed that nurses are generally approachable, $60 \%$ of doctors agreed that nurses are generally approachable. $67.9 \%$ patients agreed that nurses are usually polite and courteous, while $51.5 \%$ doctors agreed that nurses are usually polite and courteous. On the nurses' attention to the environment, $69 \%$ patients agreed to this while $57.1 \%$ doctors agreed to this. $92.8 \%$ patients agreed that the nurses always appear neat and tidy while $77.1 \%$ doctors agreed that the nurses always appear neat and tidy. As regards professional comportment and manners, $67.9 \%$ patients agreed that nurses exhibited this while on duty while 51.5\% doctors agreed that nurses exhibited this while on duty (Table 7 and Table 8).

Association between the perception of patients and doctors about the Communication Skills of Nurses: There was a significant difference between the perception of patients and doctors about the communication 


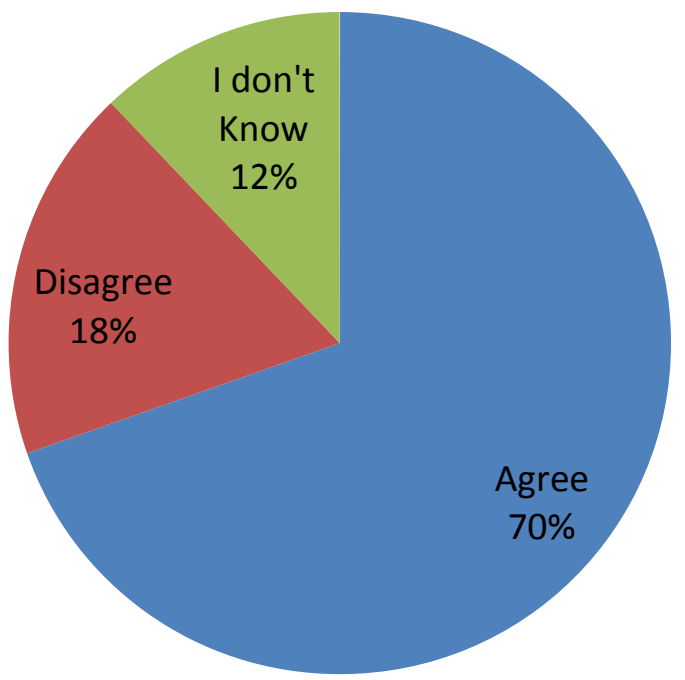

Figure 1. Perception of patients about the attitude of nurses towards their work.

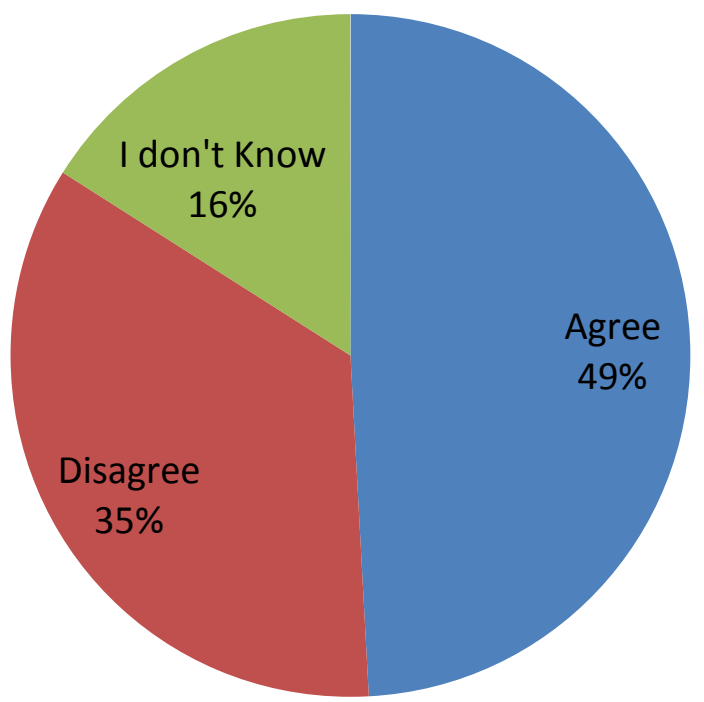

Figure 2. Perception of doctors about the attitude of nurses towards their work.

Table 3. Perception of patients about the competence of nurses.

\begin{tabular}{|c|c|c|c|c|c|c|c|c|}
\hline \multirow{2}{*}{$\begin{array}{c}\text { Items } \\
\text { Nurses }\end{array}$} & \multicolumn{2}{|c|}{ Agree } & \multicolumn{2}{|c|}{ Disagree } & \multicolumn{2}{|c|}{ I Do not Know } & \multirow{2}{*}{ Total } & \multirow{2}{*}{$\begin{array}{c}\text { Total } \\
\text { Percentage } \\
(\%)\end{array}$} \\
\hline & $\mathbf{N}$ & $\%$ & $\mathbf{N}$ & $\%$ & $\mathbf{N}$ & $\%$ & & \\
\hline Perform procedures with minimal mistakes & 124 & 75.1 & 16 & 9.7 & 25 & 15.2 & 165 & 100 \\
\hline Can handle hospital equipment & 126 & 76.4 & 21 & 12.7 & 18 & 10.9 & 165 & 100 \\
\hline Efficiently perform more than one activity at a time & 114 & 69.1 & 35 & 21.2 & 16 & 9.7 & 165 & 100 \\
\hline $\begin{array}{l}\text { Usually have good interpersonal relationship with others } \\
\text { (patients and staff) }\end{array}$ & 120 & 72.7 & 35 & 21.2 & 10 & 6 & 165 & 100 \\
\hline Possess good teaching skills & 121 & 73.4 & 22 & 13.3 & 22 & 13.4 & 165 & 100 \\
\hline Of a higher are cadre are more efficient than the junior nurses & 105 & 63.6 & 52 & 31.5 & 8 & 4.8 & 165 & 100 \\
\hline Generally have good knowledge about the patient's condition & 91 & 55.1 & 59 & 35.7 & 15 & 9.1 & 165 & 100 \\
\hline
\end{tabular}


Table 4. Perception of doctors about the competence of nurses.

\begin{tabular}{|c|c|c|c|c|c|c|c|c|}
\hline \multirow{2}{*}{\begin{tabular}{|c|} 
Items \\
Nurses
\end{tabular}} & \multicolumn{2}{|c|}{ Agree } & \multicolumn{2}{|c|}{ Disagree } & \multicolumn{2}{|c|}{ I Do not Know } & \multirow{2}{*}{ Total } & \multirow{2}{*}{$\begin{array}{c}\text { Total } \\
\text { Percentag } \\
(\%)\end{array}$} \\
\hline & $\mathbf{N}$ & $\%$ & $\mathbf{N}$ & $\%$ & $\mathbf{N}$ & $\%$ & & \\
\hline Perform procedures with minimal mistakes & 18 & 51.4 & 10 & 28.6 & 7 & 20 & 35 & 100 \\
\hline Can handle hospital equipment & 29 & 82.8 & 4 & 11.4 & 2 & 5.7 & 35 & 100 \\
\hline Efficiently perform more than one activity at a time & 17 & 48.6 & 16 & 45.7 & 2 & 5.8 & 35 & 100 \\
\hline $\begin{array}{l}\text { Usually have good interpersonal relationship } \\
\text { with others (patients and staff) }\end{array}$ & 21 & 60 & 13 & 37.2 & 1 & 2.9 & 35 & 100 \\
\hline Possess good teaching skills & 15 & 42.9 & 10 & 28.5 & 10 & 28.6 & 35 & 100 \\
\hline Of a higher are cadre are more efficient than the junior nurses & 25 & 71.4 & 6 & 17.1 & 4 & 11.4 & 35 & 100 \\
\hline Generally have good knowledge about the patient's condition & 16 & 45.7 & 17 & 48.6 & 2 & 5.8 & 35 & 100 \\
\hline
\end{tabular}

Table 5. Perception of patients about the communication skills of nurses.

\begin{tabular}{|c|c|c|c|c|c|c|c|c|}
\hline \multirow{2}{*}{$\begin{array}{c}\text { Items } \\
\text { Nurses usually }\end{array}$} & \multicolumn{2}{|c|}{ Agree } & \multicolumn{2}{|c|}{ Disagree } & \multicolumn{2}{|c|}{ I Do not know } & \multirow{2}{*}{ Total } & \multirow{2}{*}{$\begin{array}{c}\text { Total } \\
\text { Percentage } \\
(\%)\end{array}$} \\
\hline & $\mathbf{N}$ & $\%$ & $\mathbf{N}$ & $\%$ & $\mathbf{N}$ & $\%$ & & \\
\hline $\begin{array}{c}\text { Treat others (patients and other health care professionals) } \\
\text { with respect }\end{array}$ & 120 & 72.7 & 39 & 23.6 & 6 & 3.6 & 165 & 100 \\
\hline Speak with confidence & 143 & 86.7 & 16 & 9.7 & 6 & 3.6 & 165 & 100 \\
\hline Have good command of the English language & 119 & 72.1 & 34 & 20.6 & 12 & 7.3 & 165 & 100 \\
\hline Display team spirit ( among themselves) & 126 & 76.4 & 22 & 13.3 & 17 & 10.3 & 165 & 100 \\
\hline Work amicably with other members of the health team & 132 & 80 & 22 & 13.3 & 11 & 6.7 & 165 & 100 \\
\hline
\end{tabular}

Table 6. Perception of doctors about the communication skills of nurses.

\begin{tabular}{|c|c|c|c|c|c|c|c|c|}
\hline \multirow{2}{*}{$\begin{array}{c}\text { Items } \\
\text { Nurses usually }\end{array}$} & \multicolumn{2}{|c|}{ Agree } & \multicolumn{2}{|c|}{ Disagree } & \multicolumn{2}{|c|}{ I Do not know } & \multirow{2}{*}{ Total } & \multirow{2}{*}{$\begin{array}{c}\text { Total } \\
\text { Percentage } \\
(\%)\end{array}$} \\
\hline & $\mathbf{N}$ & $\%$ & $\mathbf{N}$ & $\%$ & $\mathbf{N}$ & $\%$ & & \\
\hline $\begin{array}{l}\text { Treat others } \\
\text { (patients and other health care professionals) }\end{array}$ & 18 & 51.5 & 17 & 48.6 & 0 & 0 & 35 & 100 \\
\hline Speak with confidence & 21 & 60 & 13 & 37.2 & 1 & 2.9 & 35 & 100 \\
\hline Have good command of the English language & 21 & 60 & 10 & 28.6 & 4 & 11.5 & 35 & 100 \\
\hline Display team spirit ( among themselves) & 21 & 60 & 7 & 20 & 7 & 20 & 35 & 100 \\
\hline Work amicably with other members of the health team & 18 & 51.5 & 15 & 42.9 & 2 & 5.8 & 35 & 100 \\
\hline
\end{tabular}

Table 7. Perception of patients about the professional demeanour of nurses.

\begin{tabular}{|c|c|c|c|c|c|c|c|c|}
\hline \multirow{2}{*}{\begin{tabular}{|l} 
Items \\
Nurses
\end{tabular}} & \multicolumn{2}{|c|}{ Agree } & \multicolumn{2}{|c|}{ Disagree } & \multicolumn{2}{|c|}{ I Do not know } & \multirow{2}{*}{ Total } & \multirow{2}{*}{$\begin{array}{c}\text { Total } \\
\text { Percentage } \\
(\%)\end{array}$} \\
\hline & $\mathbf{N}$ & $\%$ & $\mathbf{N}$ & $\%$ & $\mathbf{N}$ & $\%$ & & \\
\hline Are usually approachable & 117 & 70.9 & 44 & 26.6 & 4 & 2.4 & 165 & 100 \\
\hline Are usually polite and courteous & 112 & 67.9 & 49 & 29.7 & 4 & 2.4 & 165 & 100 \\
\hline Exhibit apt attention to their environment while on duty & 114 & 69 & 26 & 15.7 & 25 & 15.1 & 165 & 100 \\
\hline Always appear neat and tidy & 153 & 92.8 & 8 & 4.8 & 4 & 2.4 & 165 & 100 \\
\hline $\begin{array}{l}\text { Are usually well mannered and } \\
\text { comport themselves professionally }\end{array}$ & 112 & 67.9 & 38 & 23 & 15 & 9.1 & 165 & 100 \\
\hline
\end{tabular}


Table 8. Perception of doctors about the professional demeanor of nurses.

\begin{tabular}{|c|c|c|c|c|c|c|c|c|}
\hline \multirow{2}{*}{$\begin{array}{c}\text { Items } \\
\text { Nurses }\end{array}$} & \multicolumn{2}{|c|}{ Agree } & \multicolumn{2}{|c|}{ Disagree } & \multicolumn{2}{|c|}{ I Do not know } & \multirow{2}{*}{ Total } & \multirow{2}{*}{$\begin{array}{c}\text { Total } \\
\text { Percentage } \\
(\%)\end{array}$} \\
\hline & $\mathbf{N}$ & $\%$ & $\mathbf{N}$ & $\%$ & $\mathbf{N}$ & $\%$ & & \\
\hline Are usually approachable & 21 & 60 & 11 & 31.5 & 3 & 8.6 & 35 & 100 \\
\hline Are usually polite and courteous & 18 & 51.5 & 13 & 37.1 & 4 & 11.5 & 35 & 100 \\
\hline Exhibit apt attention to their environment while on duty & 20 & 57.1 & 9 & 25.7 & 6 & 17.2 & 35 & 100 \\
\hline Always appear neat and tidy & 27 & 77.1 & 5 & 14.3 & 3 & 8.6 & 35 & 100 \\
\hline Are usually well mannered and comfort themselves professionally & 18 & 51.5 & 12 & 34.3 & 5 & 14.3 & 35 & 100 \\
\hline
\end{tabular}

skills of nurses $(\mathrm{t}=2.423$; $\mathrm{df}=198 ; \mathrm{p}<0.05$ ). The table further revealed the (mean $=22.44$; $\mathrm{SD}=4.01$; Std. Error Mean $=0.312$ ) for patient and $($ Mean $=20.68$; SD = 3.26; Std. Error Mean $=0.552)$ for medical doctors.

Association between perception of patients and doctors about the competent of nurses: Perception of patients and doctors $(\mathrm{p}>0.05)$ does not have significant difference on the competence of nurses.

Testing the responses of the various cadres of the doctors on their perception of the competence of nurses using Anova $\alpha=0.05$.

From Table 9, there is no statistically significant relationship between the perceptions of various cadres of doctors about the competence of nurses ( $p>0.05$ ).

\section{Discussion}

The study revealed that majority of the respondents both patients and doctors alike agreed to the fact that nurses were competent in carrying out their duties except on the issue of having good knowledge about the patient's condition where majority of the doctors disagreed i.e. $48.6 \%$ as against the $45.7 \%$ that agreed. This is similar to the findings of Schmalenberg et al. [9] where the physicians rated the competency levels of nurses 8.9 out of 10, a value even higher than what the nurses rated themselves. Schmalenberg et al. [9] study further revealed that knowledge competency is evidenced primarily by questions asked and how questions are answered. Questions should be thoughtful, non-repetitive, show intellectual command of relevant knowledge and understanding. The distribution of responses for the knowledge domain shows more from staff nurses (22\%) and physicians (16\%) than from managers (3\%). Wysong and Driver [10] recognized a competent nurse as one who is able to transfer knowledge to the patient (teaching skills), handle hospital equipment, have good interpersonal relationship with those around and have good knowledge of the patient's condition. Findings from the study also revealed that majority of patients (63.6\%) and doctors (71.4\%) agrees that nurses of higher cadre were more efficient than the junior nurses this might be related to years of experience which was supported by [11] where medical residents opined that years of experience came with good clinical judgment of nurses. Though, Dougherty and Lister [4] have a contrary view that nurses of all cadres and disciplines have an ethical, moral and professional responsibility to disseminate their unique skills and knowledge to clients, colleagues, peers and fellow professionals with the utilization of good communication skills.

Patients from this study thought very highly about the communication skills of nurses than the doctors did as opposed to the study conducted by [11] who viewed nurses as poor communicators especially with the doctors. [12] on the other hand reported that effective communication with members of the heath team was a sign of good nursing competence including respect for others. Also, the findings from this study corroborates Hamilton and Martin [13], that Nurses can facilitate successful and therapeutic patient contact through good communication skills found in questioning, listening, summarizing, reflecting and paraphrasing, setting inductions and closure. These skills are used on a daily basis to: gather information; reassure; facilitate patient expression; harness attitudes, views and opinions; encourage critical thinking; reduce anxiety; facilitate liaison with other disciplines; and promote continuity in patient care

The study revealed that attitude of nurses towards their work was rated high among the patients (70\%) compared to the doctors (49\%) this corroborates the study conducted by [11], where resident doctors reported that nurses acted as though they were there for the hours and not for the patients. In Izumi, Baggs and Knafl [12] study, patients reported willingness to work as a professional attitude of competent nurses and not just being 
Table 9. Association between the various cadres of the doctors and their perception of the competence of nurses.

\begin{tabular}{cccccc}
\hline & Sum of Squares & Df & Mean Square & F & Sig. \\
\hline Between doctors of different cadres & 171.350 & 3 & 57.117 & 1.784 & 0.171 \\
Within doctors of the same cadre & 992.536 & 31 & 32.017 & & \\
Total & 1163.886 & 34 & & \\
\hline
\end{tabular}

there for the hours. Patients $(\mathrm{N}=10)$ from the same study also reported a positive attitude to work as the nurse that seemed like he/she enjoyed their work and did not show obvious pressures of the job. This also corroborates Ward [14] that the overall attitude of a caregiver affects the patient physically, spiritually, and emotionally. If the nurse is positive, the patient is more likely to have a positive attitude himself and potentially improve at a faster rate. On the other end of the spectrum, a negative attitude may affect the patient's attitude and recovery in a negative and damaging manner. It is vital that a nurse behaves positively around patients in order to aid recovery. Therefore, it is a wise idea for a nurse to be conscientious in his/her outlook and behavior at the workplace [14]. However, the study revealed that nurses should improve more on their attitude as perceived by other health care professionals. This is in line with Noe [15] that one of the benefits provided by an optimistic and positive attitude that helps to improve the working environment is that it attracts people to work together and can help everyone get through conflict and stressful situations in the workplace.

Patients and doctors in this study showed high regard for the professional demeanor of nurses. Both groups agreed that nurses are being professional in their activities (59\% of the doctors and $74 \%$ of patients).

This result is quite different from that of Wlodarczyk and Tobolska [16] which aimed at comparing the perception of the nurses' professional image by doctors, patients and nurses themselves, with the following elements of the image taken into account: professional, personal and interpersonal characteristics as well as general beliefs on the nursing profession. The study revealed that patients' and doctors' appraisal was lower than that of nurses, except for mental strength and tidiness in which the patients rated the nurses high.

Significant association was found between the perception of patients and doctors about the communication skills of nurses with a p-value of 0.016. According to Xaxx [17], good nurses understand the need to maintain open channels of communication with doctors, co-workers, administrators and, most importantly, patients. Hamilton and Martin [13] in support of this stated that one of the basics of good nursing is good communication with patients and other health professionals. In congruence with this is the fact that the King's conceptual model also sees the need for effective communication within the interpersonal system for the achievement of goal attainment.

There was no significant association between the perception of patients and doctors about the competence of nurses with a p-value of 0.132 . Competence is a function of knowledge, psychomotor abilities and good interpersonal skills [2]. All these are important for a healthy relationship between the nurse and the patient and between the nurse and other health care professionals.

There was no significant association between the various cadres of the doctors and their perception on the competence of nurses. The study assessed the perception of consultants $(n=10)$, senior registrars $(n=11)$, registrars $(n=8)$ and house officers $(n=6)$. Results revealed no significant difference between their responses with a p-value of 0.171 .

\section{Conclusion}

There is a need for nurses to develop themselves in all ramifications of practice so as to work harmoniously with other health care professionals and become better caregivers. Self-assessment and periodic evaluation by patients and other health care workers which could lead to changes in practice where necessary should be done. This should be documented and disseminated in order to provide checks and balances in their practice.

\section{References}

[1] Current Nursing (2010) Nursing Standards. http://www.currentnursing.com/nursing_management/nursing_standards.html

[2] Jooste K. (2010) A Framework for Recognition of Prior Learning within a Postgraduate Diploma of Nursing Manage- 
ment in South Africa. Journal of Nursing Management, 18, 704-714.

http://onlinelibrary.wiley.com/doi/10.1111/j.1365-2834.2010.01160.x/abstract

[3] Nursing and Midwifery Council of Nigeria (2005) History; Origin of Nursing in Nigeria. www.nmcnigeria.org

[4] Dougherty, L. and Lister, S. (2008) The Royal Marsden Hospital Manual of Clinical Nursing Procedures. 7th Edition, Blackwell Publishing, Oxford.

[5] Gokenbach, V. (2011) Professionalism in Nursing: What Does It Really Mean? www.nursetogether.com

[6] Williams, L. (2001) Imogene King's Interacting Systems Theory: Application in Emergency and Rural Nursing. Online Journal of Rural Nursing and Health Care, 12, 102-117. www.rno.org/journal/index.php/online-journal/article/view/93/89

[7] Alligood, M.R. and Tomey, A. (2002) Nursing Theorists and Their Work. 5th Edition, Mosby Inc., St. Louis. www.us.elsevierhealth.com

[8] Limjaroen, K. (2012) Perceived Patients’ Rights by Health Care Workers and Patients. Chulalongkorn University, Bangkok, 1, 50-66.

[9] Schmalenberg, C., Kramer, M., Brewer, B.B., Burke, R., et al. (2008) Clinically Competent Peers and Support for Education: Structures and Practices That Work. Critical Care Nurse, 28, 54-65. http://ccn.aacnjournals.org

[10] Wysong, P.R. and Driver, E. (2009) Patients’ Perceptions of Nurses’ Skill. Critical Care Nurse, 29, $24-37$. http://ccn.aacnjournals.org http://dx.doi.org/10.4037/ccn2009241

[11] Weinberg, D., Miner, D. and Rivlin, L. (2009) “It Depends”: Medical Residents’ Perspectives on Working with Nurses. American Journal of Nursing, 109, 34-43. www.nursingcenter.com http://dx.doi.org/10.1097/01.NAJ.0000357167.63636.98

[12] Izumi, S., Baggs, J.G. and Knafl, K.A. (2010) Quality Nursing Care for Hospitalized Patients with Advanced Illness: Concept Development. Research in Nursing \& Health, 33, 299-315. www.ncbi.nlm.nih.gov http://dx.doi.org/10.1002/nur.20391

[13] Hamilton, S.J. and Martin, D.J. (2007) A Framework for Effective Communication Skills. Extended Version of Nursing Times, 103, 30-31. www.nursingtimes.net

[14] Ward, M. (2009) Nursing: The Effects of a Nurse’s Attitude. http://maryward.edublogs.org

[15] Noe, D. (2010) Why Attitude Is Important in the Work Place. www.helium.com

[16] Wlodarczyk, D., Tobolska, B., et al. (2011) Professional Image of Nurses as Perceived by Doctors, Patients and Nurses Themselves. Medycyna Pracy, 62, 269-279. www.pubmed.com

[17] Xaxx, J. (2012) The Significance of Communication in the Nursing Workplace. http://www.ehow.com/info_8180366_significance-communication-nursing-workplace.html\#ixzz21y4tVOkJ 
Scientific Research Publishing (SCIRP) is one of the largest Open Access journal publishers. It is currently publishing more than 200 open access, online, peer-reviewed journals covering a wide range of academic disciplines. SCIRP serves the worldwide academic communities and contributes to the progress and application of science with its publication.

Other selected journals from SCIRP are listed as below. Submit your manuscript to us via either submit@scirp.org or Online Submission Portal.
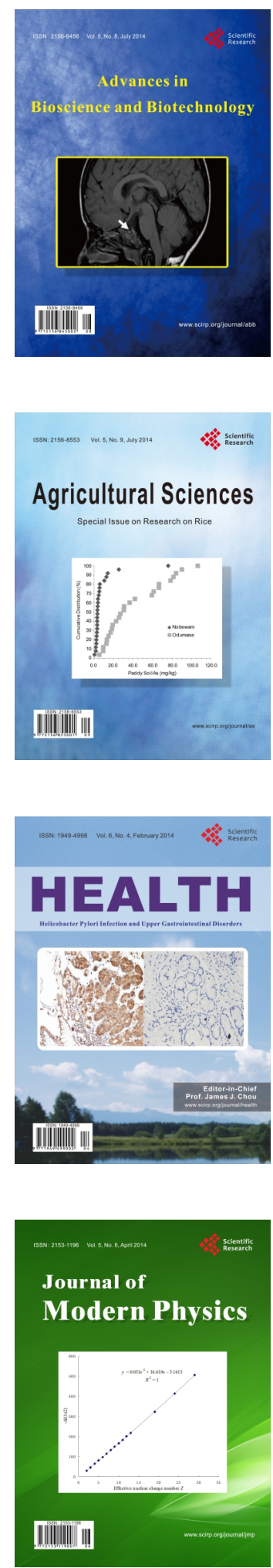
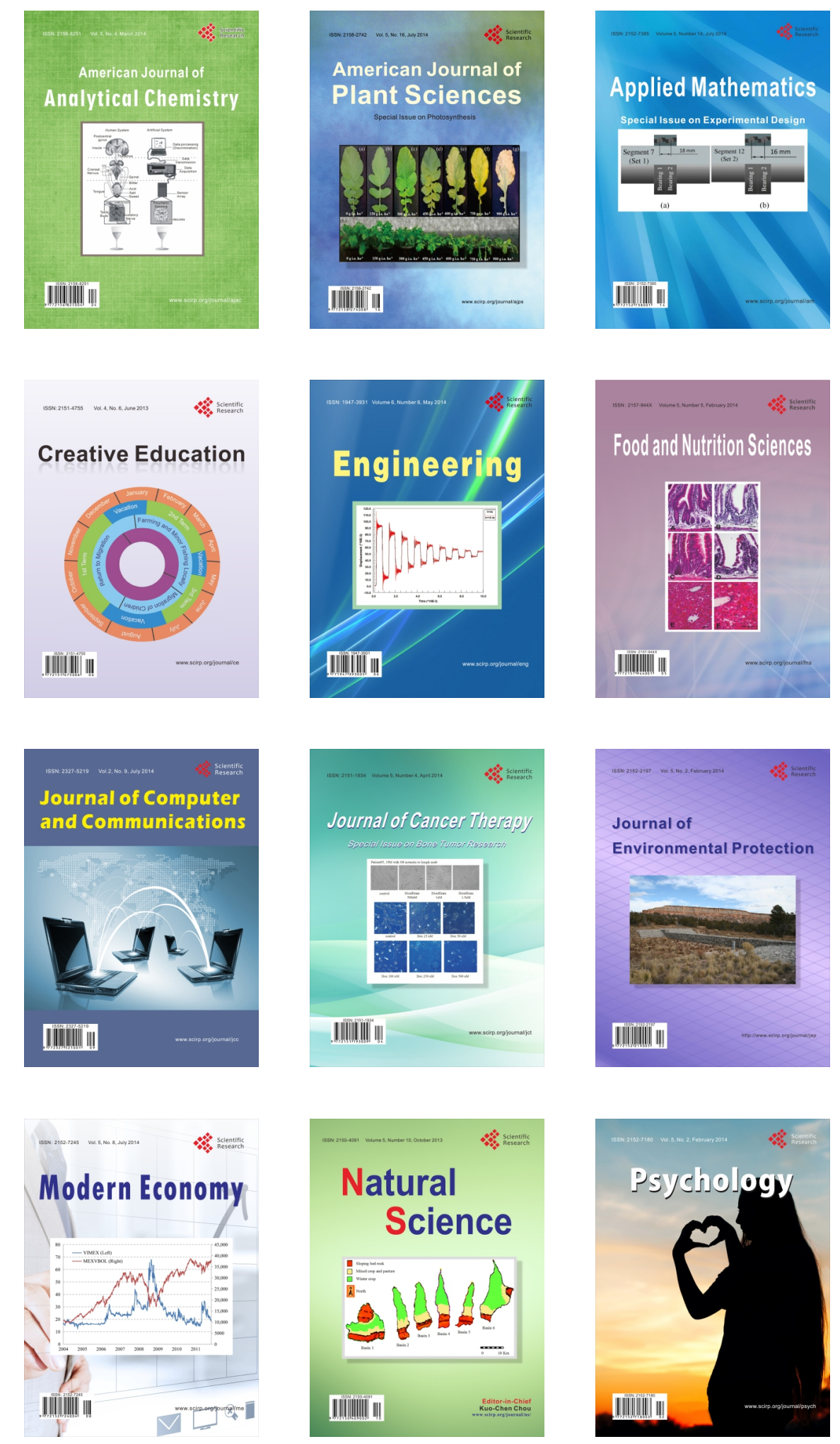